\title{
A redesigned follitropin alfa pen injector for infertility: results of a market research study
}

\author{
This article was published in the following Dove Press journal: \\ Patient Preference and Adherence \\ 27 June 2011 \\ Number of times this article has been viewed
}

\section{Carole Abbotts' \\ Cristiana Salgado-Braga ${ }^{2}$ \\ Céline Audibert-Gros ${ }^{3}$ \\ 'Pharmaceutical Marketing Research Consultancy, London, UK; ${ }^{2}$ Fertility and Endocrinology Global Business Unit, ${ }^{3}$ Business Intelligence, Merck Serono SA, Geneva, Switzerland}

Background: The purpose of this study was to evaluate patient-learning and nurse-teaching experiences when using a redesigned prefilled, ready-to-use follitropin alfa pen injector.

Methods: Seventy-three UK women of reproductive age either administering daily treatment with self-injectable gonadotropins or about to start gonadotropin treatment for infertility (aged 24-47 years; 53 self-injection-experienced and 20 self-injection-naïve) and 28 nurses from UK infertility clinics were recruited for the study. Following instruction, patients and nurses used the redesigned follitropin alfa pen to inject water into an orange and completed questionnaires to evaluate their experiences with the pen immediately after the simulated injections.

Results: Most $(88 \%, \mathrm{n}=64)$ patients found it easy to learn how to use the pen. Among injectionexperienced patients, $66 \%(\mathrm{n}=35)$ agreed that the redesigned pen was easier to learn to use compared with their current method and $70 \%(\mathrm{n}=37)$ also said they would prefer its use over current devices for all injectable fertility medications. All nurses considered the redesigned pen easy to learn and believed it would be easy to teach patients how to use. Eighty-six percent $(n=24)$ of the nurses thought it was easy to teach patients to determine the remaining dose to be dialed and injected in a second pen if the initial dose was incomplete. Compared with other injection devices, $96 \%(\mathrm{n}=27)$ thought it was "much easier" to "as easy" to teach patients to use the redesigned pen. Based on ease of teaching, $68 \%(n=19)$ of nurses would choose to teach the pen in preference to any other injection method. Almost all $(93 \%, \mathrm{n}=26)$ nurses considered that having the same pen format for a range of injectable gonadotropins would facilitate teaching and learning self-injection.

Conclusion: In this market research study with infertile patients and infertility nurses, the redesigned follitropin alfa pen was perceived as easy to learn, easy to teach how to use, and well accepted.

Keywords: infertility, gonadotropin, follitropin alfa pen, prefilled pen device, recombinant human follicle-stimulating hormone

\section{Introduction}

Daily injections of urinary or recombinant gonadotropins are often used to treat infertile patients and may include human follicle-stimulating hormone with or without the addition of luteinizing hormone. These gonadotropin products are often selfinjected to promote follicular development as part of the treatment plan for assisted reproductive technologies, such as ovulation induction combined with natural intercourse, intrauterine insemination, or in vitro fertilization. At the end of the controlled ovarian stimulation phase with injectable gonadotropins, a single injection of human chorionic gonadotropin may be used to promote final follicular maturation and to trigger ovulation.
Correspondence: Cristiana Salgado-Braga Fertility Global Marketing, Merck Serono SA, 9 Chemin des Mines, 1202 Geneva, Switzerland

$\mathrm{Tel}+41224144127$

Fax +41224143062

Email cristiana.braga@merckserono.net 
The need for daily subcutaneous injections in infertility treatment does not tend to impair treatment adherence, but there is patient anxiety surrounding whether the correct dose has been delivered and the fact that unconscious mistakes can be made. ${ }^{1}$ To improve compliance with treatment, it is important that devices used for the administration of recombinant human gonadotropins are easy for patients to learn to use, as well as easy for nurses in charge of patient training to teach. Currently, the majority of gonadotropin products are administered via syringes or prefilled pen injection devices, which have been introduced in the last decade to try to improve patient convenience and ease of use.

A key attribute of any injection device is the number of steps required to prepare and administer the injection. Fewer and easier steps are likely to reduce injection errors and to contribute to patient confidence.

The original pen injector for administration of follitropin alfa (recombinant human follicle-stimulating hormone) was modified to include built-in, enhanced, patient-friendly features, including visually improved numbering on the dose-setting dial in a second-generation pen. The thirdgeneration redesigned follitropin alfa pen injector used in this study is a multidose, ready-to-use prefilled pen that incorporates several new and improved features. These features include a dose display window with a magnifying glass lid to enlarge the dosing number, which shows only the selected preset dose, the return of the dose reading to zero after injection of the full prescribed dose, or information on how much residual dose is required with a second pen if the full dose has not been administered, and a fully transparent cartridge container with graduated markings, to assist the user in determining the approximate amount of product left in the pen. The pen is available in three dose presentations of follitropin alfa, ie, $300 \mathrm{IU}, 450 \mathrm{IU}$, and 900 IU. A key feature of the pen is that it offers flexibility in individualization of treatment protocols with a wide range of dose increments, ie, 12.5-300 IU for the $300 \mathrm{IU}$ pen and 12.5-450 IU for the $450 \mathrm{IU}$ and $900 \mathrm{IU}$ pens. Results of the dose accuracy testing of the 900 IU presentation of the redesigned follitropin alfa pen injector, performed in accordance with international standards (EN ISO 11608-1:2000), demonstrated that the pen can accurately deliver a wide range of doses. ${ }^{2}$

The objective of this market research study was to assess the ease of teaching by fertility nurses on how to use the redesigned follitropin alfa pen injector, as well as the ease of learning to use the pen by infertile patients undergoing ovarian stimulation with gonadotropins.

\section{Materials and methods}

This study was conducted in the UK in January-February 2011 (London, Birmingham, Southampton, Manchester, Glasgow, and Newcastle). Patients and nurses were recruited by Insight Research Group, London, UK, based on the criteria outlined below. All participants provided informed consent.

\section{Study participants}

Patients eligible for inclusion in this study were women of reproductive age who were either undergoing controlled ovarian stimulation or had previous experience with daily injections of gonadotropin products within the last 6 months, or were injection-naïve with no previous experience with injectable medications but were consulting with a fertility clinic and were about to start gonadotropin treatment for infertility.

Nurses working in infertility centers and responsible for teaching patients undergoing fertility treatment to use selfinjection devices (syringes and pens) were also included in the study. Nurses had to teach at least 10 patients in an average month, spend $80 \%$ of their working time in infertility clinics and have 3-30 years experience of working in an infertility clinic to be eligible for inclusion.

\section{Training procedures and study questionnaires}

Patient-learning and nurse-teaching experiences when using the redesigned follitropin alfa prefilled pen (GONAL- $\mathrm{f}^{\circledR /}$ GONAL- $\mathrm{f}^{\circledR}$ Revised Formulation Female Prefilled Pen, Merck Serono SA, Geneva, Switzerland, an affiliate of Merck KGaA, Darmstadt, Germany, Figure 1) were evaluated in this market research study. Before a moderator presented and demonstrated the operation of the pen injector

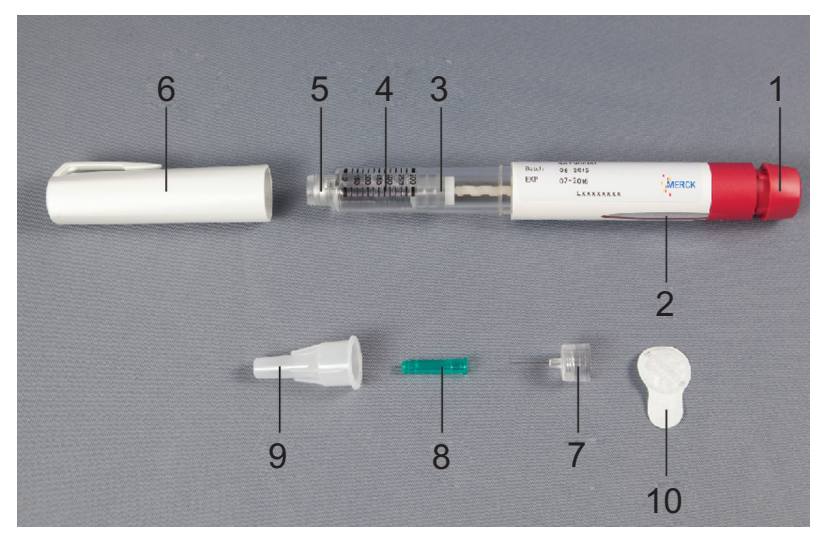

Figure I The components of the redesigned follitropin alfa pen injector: I, dosesetting knob; 2, dose display; 3, plunger piston; 4, graduated reservoir holder; 5 , threaded needle connector; 6 , pen cap; 7 , removable needle; 8 , inner needle shield; 9, outer needle cap; 10, peel-off seal tab. The pen barrel and cartridge comprise sections I-5. 
to the nurses, they completed part of an online nurses' questionnaire (Appendix 1) pertaining to use and perceptions of existing devices for administering fertility treatment. To ensure consistent demonstration of the pen injector, the moderator followed a script that outlined step-by-step written and diagrammatic instructions. This was also available to nurses as additional guidance in handling the pen. After receiving the verbal and written instructions, nurses were each given a new, unbranded 900 IU demonstration pen, prefilled with water for injection, and were asked to attach the needle, practice removing large air bubbles, and inject $125 \mathrm{IU}$ of water into an orange as many times as required to gain familiarity with the pen injector. Nurses then completed the part of the nurses' questionnaire on ease of learning. The nurses then repeated the process, training small groups of up to five patients per nurse. The moderator ensured that an accurate demonstration of the pen injector was provided to patients.

For assessment of acceptance of the redesigned follitropin alfa pen, nurses completed the relevant questions on their questionnaire and patients completed a separate online patient questionnaire (Appendix 2). Each step of the injection process with the pen was assessed to determine both how easy it was to teach and to learn in terms of priming, attaching the needle, reading the dosing scale, setting the dose, pushing the dose setting knob when injecting, and checking that the full dose had been injected. Respondents also evaluated how easy it was to determine the remaining dose to be dialed and injected with a second pen if the initial dose was incomplete, readjust the dose if needed, and remove the needle. Nurses and treatmentexperienced patients also compared the attributes of this pen injector with the self-injection devices that they currently taught or used, based on recall. The entire process of instruction, practice, and completing the questionnaire took approximately 70 minutes for nurses and 40 minutes for patients.

The redesigned prefilled follitropin alfa 900 IU demonstration pens were supplied by the manufacturer. All materials were new before assessment by each patient/nurse.

\section{Statistical analysis}

Data from nurse and patient questionnaires are presented using descriptive statistics. Scales rating key performance indicators used a 5-point scale where 5 was the best and 1 was the worst possible outcome. Questions on preferences and advantages did not use rating scales and are quoted as a percentage of participants who provided each response.

\section{Results}

Seventy-three infertile women of reproductive age and 28 nurses who had worked for 3-30 years in an infertility clinic were enrolled in this study; the numbers of patients and nurses recruited from each city are shown in Table 1.

Patients had a mean age of 35 (range 24-47) years and $8 \%$ were left-handed $(n=6)$. The baseline characteristics of the patients are summarized in Table 2; 73\% $(n=53)$ of patients were treatment-experienced and $27 \%(n=20)$ were treatment-naïve.

The nurses all spent at least $80 \%$ of their time working directly with patients and personally teaching women how to use injectable gonadotropins in pens or syringes/vials for fertility treatment; $7 \%$ were left-handed $(n=2)$. Injectable gonadotropin devices that nurses had taught patients to use in the previous 6 months are summarized in Table 3 .

All of the patients/nurses participated in the training and completed all the sections of the questionnaires that were relevant to their experiences, ie, self-injection-naïve patients did not answer questions aimed at self-injection-experienced patients.

\section{Patients}

The specific aspects of the redesigned pen injector that patients considered easy to learn are shown in Figure 2. Eighty-eight percent $(n=64)$ of patients found the whole process easy to follow and had no trouble learning how to use the pen; $70 \%(n=51)$ found it easy to learn how to set the dose and how to remove large air bubbles before use.

In the total patient population, $89 \%(n=65)$ of patients were either "very" or "quite comfortable" with the zero reading on the dosing scale indicating that the full dose had been injected and $88 \%(n=64)$ with pen control when injecting. The flexibility to readjust the dose, if the set dose was too high/low, was seen as an advantage in learning how to use the pen by $85 \%(n=62)$ of patients.

Most $(95 \%, n=69)$ patients "strongly/somewhat agreed" that they were comfortable with the number of steps involved

Table I Number of nurses and patients recruited from each UK city

\begin{tabular}{lll}
\hline City & Nurses & Patients \\
\hline Birmingham & 3 & 7 \\
Manchester & 2 & 6 \\
Newcastle & 3 & 9 \\
Glasgow & 3 & 5 \\
Southampton & 5 & 14 \\
London & 12 & 32 \\
Total & 28 & 73 \\
\hline
\end{tabular}


Table 2 Demographic characteristics of the study patients $(n=73)$

\begin{tabular}{ll}
\hline Characteristics & \\
\hline Mean (SD) age, years & $35(4.54)$ \\
Left-handed, $\mathrm{n}(\%)$ & $6(8)$ \\
Age group, $\mathrm{n}(\%)$ & $13(\mathrm{I})$ \\
$24-30$ years & $30(4 \mathrm{I})$ \\
$3 \mathrm{I}-35$ years & $21(29)$ \\
$36-40$ years & $9(\mathrm{I} 2)$ \\
$4 \mathrm{I}-47$ years & \\
Fertility treatment cycles using self-injected & \\
gonadotropins undertaken in total, $\mathrm{n}(\%)^{\mathrm{a}}$ & $20(27)$ \\
0 & $22(30)$ \\
$\mathrm{I}$ & $14(19)$ \\
2 & $6(8)$ \\
3 & $4(5)$ \\
4 & $7(10)$ \\
$5+$ & \\
Current devices used to inject fertility & \\
medication, $\mathrm{n}(\%)^{\mathrm{b}}$ & $20(27)$ \\
None & $15(2 \mathrm{I})$ \\
Follitropin alfa pen & \\
Follitropin beta pen & \\
Syringe and vial & $8(\mathrm{II})$ \\
\hline
\end{tabular}

Notes: aPercentages do not total $100 \%$ due to rounding; ${ }^{b}$ percentages do not total $100 \%$ due to use/teaching of $>$ I device; 'Merck Serono SA, Geneva, Switzerland; dMerck Sharp and Dohme Ltd, Hoddesdon, Hertfordshire, UK.

Abbreviation: SD, standard deviation.

in preparing and giving the injection, and 93\% $(\mathrm{n}=68)$ believed that using the new pen device would ensure that they set the correct dose and administered it in full when they self-injected at home.

Among the injection-experienced patients, $66 \%(\mathrm{n}=35)$ considered that the redesigned follitropin alfa pen was easier to learn to use than their current injection method; the pen performance was rated as "very high" or "high" by $83 \%(n=44)$ of patients for ease of learning to remove a

Table 3 Injectable gonadotropin devices that nurses $(n=28)$ had taught patients to use in the previous six months

\begin{tabular}{ll}
\hline Device & $\mathbf{n ~ ( \% ) ^ { \mathrm { a } }}$ \\
\hline Follitropin alfa pen $^{\mathrm{b}}$ & $24(86)$ \\
Follitropin alfa syringe/vial $^{\mathrm{b}}$ & $13(46)$ \\
Lutropin alfa syringe/vial $^{\mathrm{b}}$ & $3(\mathrm{II})$ \\
Chorionic gonadotropin prefilled syringe $^{\mathrm{b}}$ & $26(93)$ \\
Follitropin beta pen $^{\mathrm{c}}$ & $9(32)$ \\
Follitropin beta syringe/vial $^{\mathrm{c}}$ & $2(7)$ \\
Chorionic gonadotropin syringe/vial $^{\mathrm{c}}$ & $14(50)$ \\
Menotropins syringe/vial $^{\mathrm{d}}$ & $25(89)$ \\
Menotropins syringe/vial $^{\mathrm{e}}$ & $6(2 \mathrm{I})$ \\
Urofollitropin syringe/vial $^{\mathrm{e}}$ & $7(25)$ \\
Chorionic gonadotropin syringe/vial $^{\mathrm{d}}$ & $2(7)$ \\
\hline
\end{tabular}

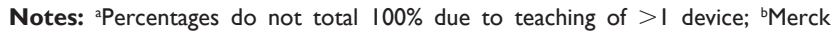
Serono SA, Geneva, Switzerland; 'Merck Sharp and Dohme Ltd, Hoddesdon, Hertfordshire, UK; ${ }^{d}$ Ferring International Center SA, Saint-Prex, Switzerland; eIBSA Institut Biochimique SA, Lugano, Switzerland. large air bubble, by $81 \%(n=43)$ for attaching the needle onto the pen, by $79 \%(\mathrm{n}=42)$ for reading the dosing scale, and by $74 \%(\mathrm{n}=39)$ for reading the graduated markings on the reservoir holder. Eighty-seven percent $(n=46)$ of the injection-experienced patients found it easy to learn how to set the dose, $89 \%(n=47)$ to push the dose setting knob when injecting, $89 \%(n=47)$ to check that the full dose had been injected, $72 \%(\mathrm{n}=32)$ to detach and discard the needle, and $81 \%(n=43)$ to determine any remaining dose required with a second pen if the initial dose administered was incomplete. Of these injection-experienced patients, $70 \%(n=37)$ claimed they would prefer to use the redesigned follitropin alfa pen over their current injection device in the future for all their injectable fertility medications (Figure 3).

The number of patients with previous experience of the Puregon ${ }^{\circledR}$ pen was small $(n=8)$, reflecting the low number of Puregon pen users in the UK and, therefore, is insufficient to draw any specific conclusions regarding device preference.

\section{Nurses}

All nurses agreed that it was easy to learn how to use the redesigned pen and believed it would be easy to teach patients how to use it. Based on ease of teaching, $68 \%(n=19)$ of the nurses would choose to teach the redesigned pen in preference to any other pen or syringe/vial currently available (Figure 4).

Regarding aspects of the pen that were easy to teach, 93\% ( $\mathrm{n}=26)$ of nurses thought it was "very" or "somewhat" easy to teach patients the overall process of self-administering a dose (Figure 5). Compared with other pen injectors, 96\% $(\mathrm{n}=27)$ of nurses thought it was "much easier" to "as easy" to teach patients to use the redesigned follitropin alfa pen; $46 \%$ ( $n=13$ ) thought it was "much" or "somewhat" easier to teach patients to use the redesigned follitropin alfa pen, and 50\% $(\mathrm{n}=14)$ considered it was neither easier nor harder. Almost all $(96 \%, \mathrm{n}=27)$ nurses rated as "very" or "quite" high, the range of possible doses that could be administered (due to a greater number of dosing increments), and 79\% ( $\mathrm{n}=22)$ were confident that the patient would be able to calculate correctly any remaining dose needed with a second pen if an incomplete dose was injected with the first pen.

It was "strongly" or "somewhat" agreed by $93 \%(\mathrm{n}=26)$ of nurses that having the same pen format for a range of injectable gonadotropins would make it easier for them to teach patients to self-inject and for patients to learn how to selfinject; $86 \%(n=24)$ of nurses agreed that the redesigned pen would significantly reduce their teaching time with patients, $89 \%(n=25)$ thought it would reduce mistakes when patients 


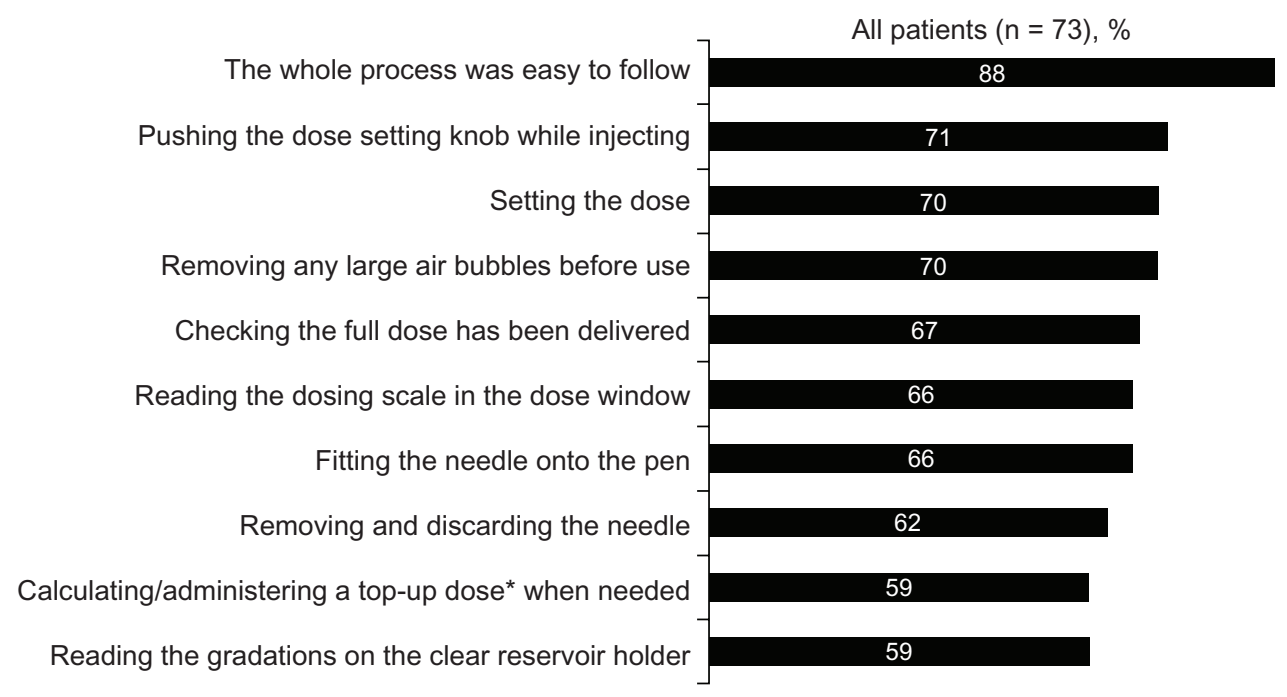

Figure 2 Aspects of the redesigned follitropin alfa pen that patients found easy to learn. Note: *Top-up dose; remainder of dose to be dialed and injected in a second pen.

self-administered at home, and $96 \%(\mathrm{n}=27)$ believed that, given a choice, patients would prefer the same pen format for administering all their injectable gonadotropin products.

\section{Discussion}

This is the first study to report patient and nurse opinions on the redesigned follitropin alfa pen for infertility treatment. Patients with infertility, who currently require numerous administration devices to deliver the full spectrum of gonadotropins during infertility treatment, ${ }^{3}$ found the pen injector easy to use and most patients found the training on use easy to follow. Among the attributes of the redesigned pen, patients rated highly the ease of checking that the full dose had been injected and the flexibility to readjust the set dose. Self-injection-experienced patients generally preferred the redesigned pen over their existing injection devices.

There are several reports that infertile patients find pen injectors simpler and easier to use than other administration methods. ${ }^{1,4-7}$ In a study of nurse-led training on administration of follicle-stimulating hormone, 123 participants attended training and completed a questionnaire. Of the patients who expressed a preference, $94 \%$ preferred a pen device to a reconstitution and conventional needle and syringe method. The most common reasons given for selection of a prefilled

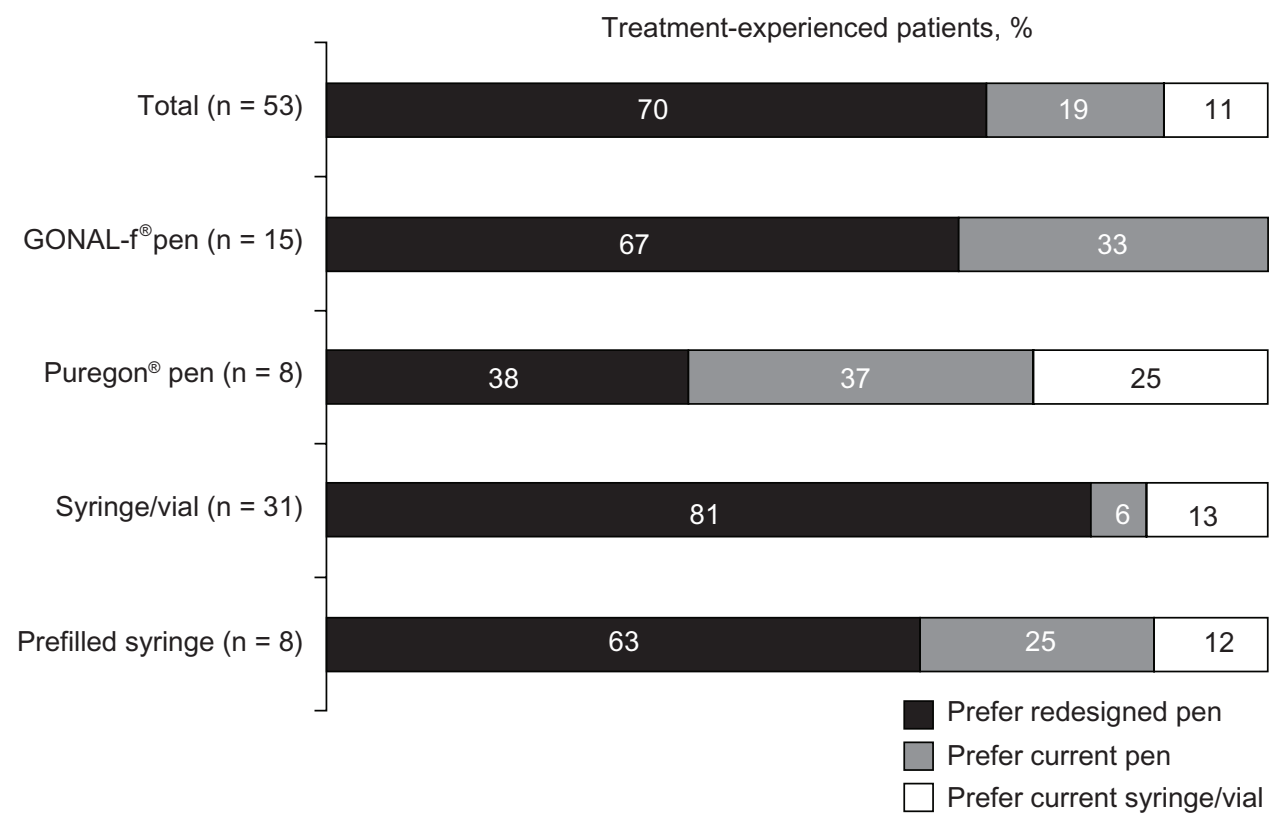

Figure 3 Summary of device preferences by injection-experienced patients. 


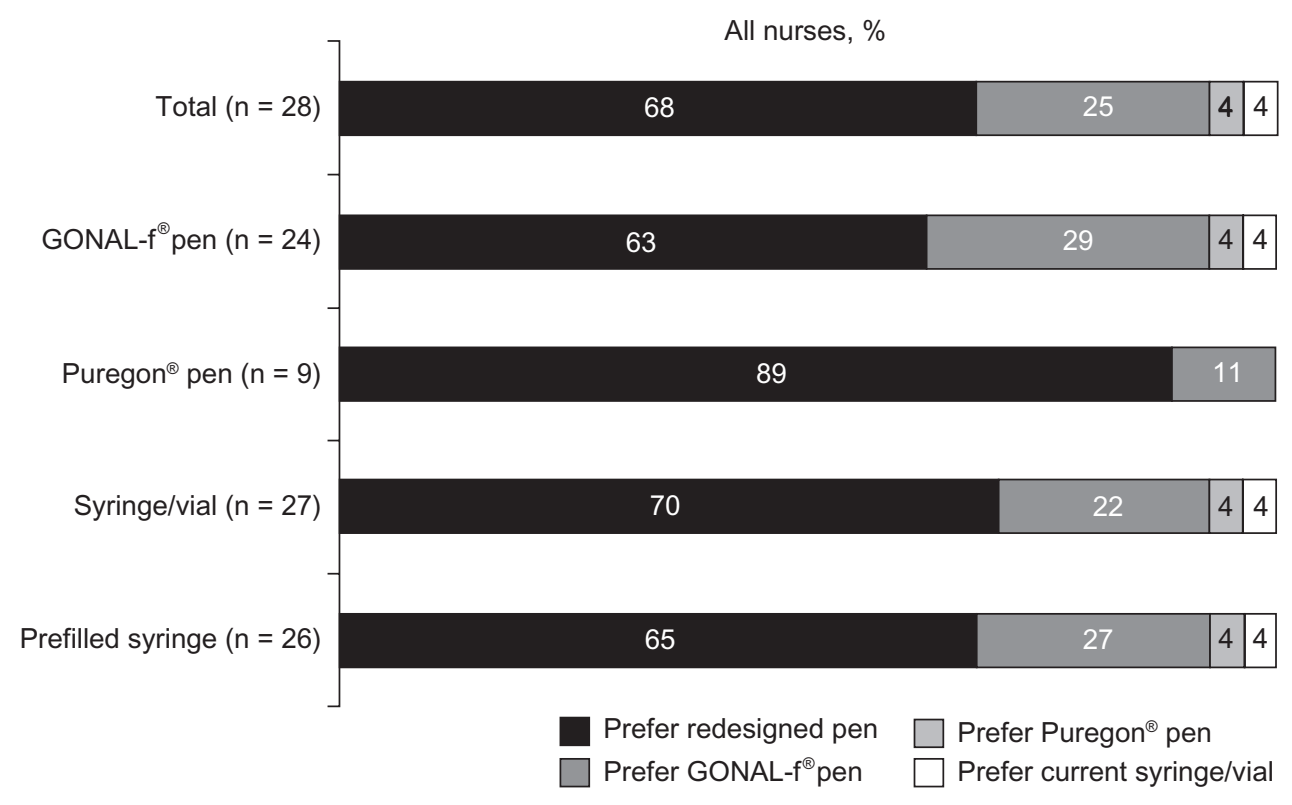

Figure 4 Summary of device preference by infertility nurses teaching patients to self-inject.

pen were that it was considered to be easy to use, had a simple and reliable dosing mechanism, and minimized the chance of making a dosing error. ${ }^{1}$

Prefilled disposable insulin pen injectors have received positive ratings for intuitiveness, instruction time, ease of use, and acceptance in patient surveys. ${ }^{8,9}$ Among patients with rheumatoid arthritis, a pen injector for a monoclonal antibody scored well compared with a prefilled syringe in terms of pain and time to inject and was perceived to be easier to use and more convenient. ${ }^{10}$

All the infertility nurses in this study found the pen injector easy to learn to use and believed that it would be easy to teach patients to use. Most nurses considered that having the same device for a range of injectable gonadotropins would facilitate teaching patients to self-inject and would reduce teaching time. These results are in agreement with those from

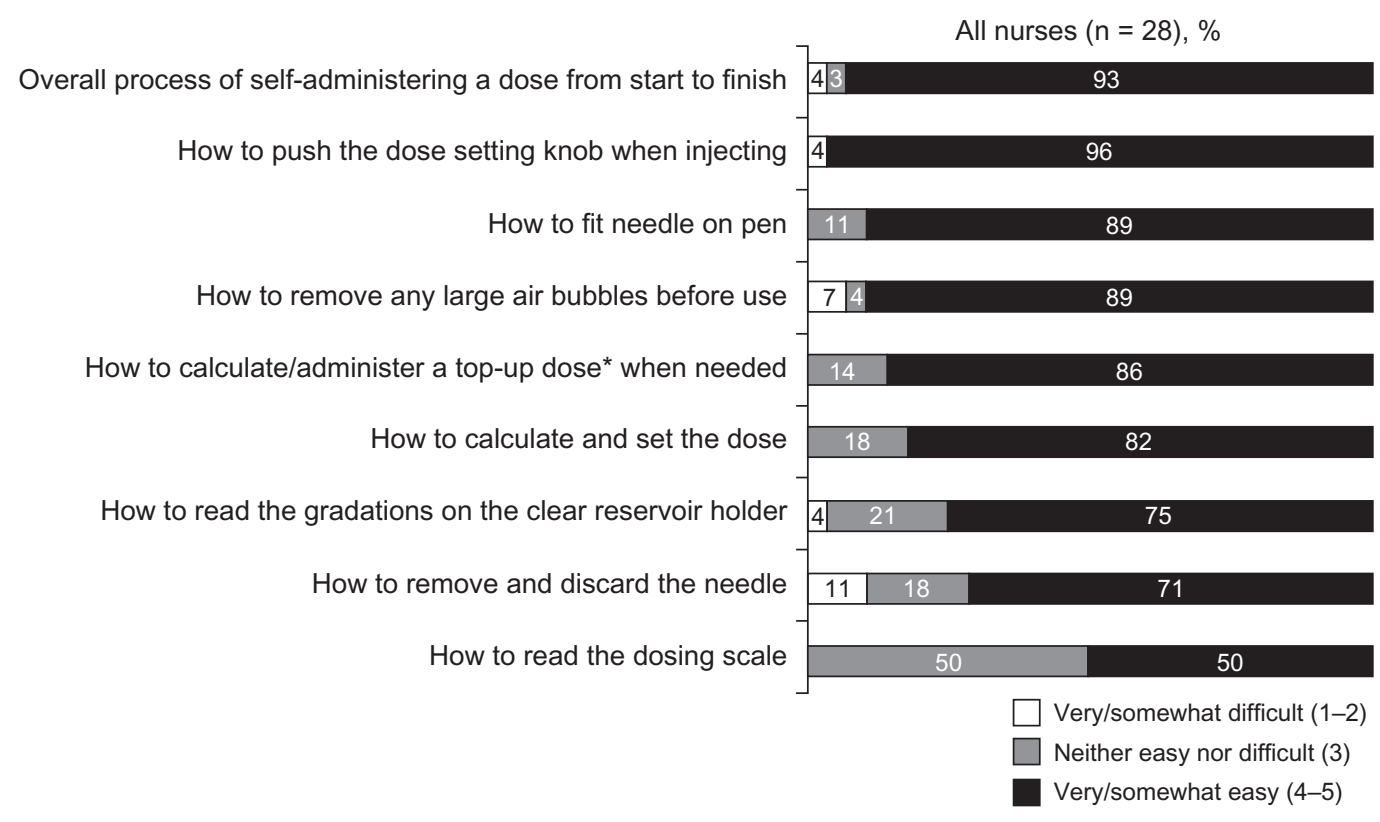

Figure 5 Fertility nurses' opinion of ease of teaching for each of the functions of the redesigned follitropin alfa pen. Note: *Top-up dose; remainder of dose to be dialed and injected in a second pen. 
another study in which pen injectors have been reported to be well received by nurses. ${ }^{11}$

Patients may use several different administration devices to deliver the full spectrum of gonadotropins during infertility treatment, so there is a need to harmonize the administration devices for infertility. A device that could be used to administer the full range of gonadotropins would have advantages for nurses in terms of teaching time and for patients in terms of learning time. The use of a common device is also likely to reduce administration errors.

A limitation of the present study was that only the redesigned follitropin alfa pen was tested and the answers about the devices that were used currently were based on recall. However, $73 \%$ of patients interviewed were self-injectionexperienced and had received fertility treatment with injectable gonadotropins in the previous six months. Thus, it is considered that results based on patient recall were unlikely to have biased the patients' answers. In addition, the study was performed in a viewing facility, was open-label and uncontrolled, and assessed perceived ease of learning and ease of teaching of the pen device rather than use in an actual fertility treatment cycle. Further studies are needed to confirm the findings in clinical practice.

\section{Conclusion}

In this market research study with infertile patients and infertility nurses, the redesigned follitropin alfa pen was perceived as easy to learn and easy to teach how to use, and was well-accepted. There was also a high level of confidence among participants that the full dose of gonadotropin had been injected properly and that it was easy to learn how to check that the correct dose had been delivered. Moreover, most nurses considered that a single platform for delivery of the full spectrum of infertility medications that a patient might require during treatment would have advantages for teaching and learning use for administration.

\section{Acknowledgments}

The authors thank the patients and nurses for their participation, and Insight Research Group, London, UK, for conducting the study. The authors also thank Jane Davies and Carol Cooper of Caudex Medical (supported by Merck Serono SA, Geneva, Switzerland, an affiliate of Merck KGaA, Darmstadt, Germany) for their assistance in the preparation of this manuscript.

\section{Disclosure}

This research and its publication were funded by Merck Serono SA, Geneva, Switzerland (an affiliate of Merck KGaA, Darmstadt, Germany). CSB and CAG are employees of and CA is a consultant for Merck Serono SA.

\section{References}

1. Weiss N. Gonadotropin products: Empowering patients to choose the product that meets their needs. Reprod Biomed Online. 2007;15: 31-37.

2. Christen M, Schertz J, Arriagada P, et al. The redesigned follitropin alfa pen injector for infertility treatment. Expert Opin Drug Deliv. 2011;8:833-839.

3. Papanikolaou EG, Kolibianakis E, Devroey P. Emerging drugs in assisted reproduction. Expert Opin Emerg Drugs. 2005;10:425-440.

4. Aghssa MM, Azargoon A, Ramezanzadeh F, et al. A comparison of the efficacy, tolerability, and convenience of two formulations of follitropinalpha in Iranian woman undergoing intracytoplasmic sperm injection cycles. Fertil Steril. 2008;90:1043-1048.

5. Rama Raju GA, Suryanarayana K, Jaya PG, et al. Comparison of follitropin-beta administered by a pen device with conventional syringe in an ART programme - a retrospective study. $J$ Clin Pharm Ther. 2008;33:401-407.

6. Sedbon E, Wainer R, Perves C. Quality of life of patients undergoing ovarian stimulation with injectable drugs in relation to medical practice in France. Reprod Biomed Online. 2006;12:298-303.

7. Somkuti SG, Schertz JC, Moore M, et al. Patient experience with follitropin alfa prefilled pen versus previously used injectable gonadotropins for ovulation induction in oligoanovulatory women. Curr Med Res Opin. 2006;22:1981-1996.

8. Asakura T, Jensen KH. Comparison of intuitiveness, ease of use, and preference in two insulin pens. J Diabetes Sci Technol. 2009;3: 312-319.

9. Reimer T, Hohberg C, Pfutzner AH, et al. Intuitiveness, instruction time, and patient acceptance of a prefilled insulin delivery device and a reusable insulin delivery device in a randomized, open-label, crossover handling study in patients with type 2 diabetes. Clin Ther. 2008;30: $2252-2262$.

10. Kivitz A, Cohen S, Dowd JE, et al. Clinical assessment of pain, tolerability, and preference of an autoinjection pen versus a prefilled syringe for patient self-administration of the fully human, monoclonal antibody adalimumab: The TOUCH trial. Clin Ther. 2006;28: $1619-1629$.

11. Porter R, Kissel C, Saunders H, et al. Patient and nurse evaluation of recombinant human follicle-stimulating hormone administration methods: Comparison of two follitropin injection pens. Curr Med Res Opin. 2008;24:727-735. 


\section{Appendix I}

Nurse questionnaire. Duration sections 1 and 2, approximately five minutes; section 3, approximately 15 minutes.

\section{Section I}

Usage and perception of existing devices.

1A. Are you left or right-handed? (Ask all, single code only.)

\begin{tabular}{|l|l|l|}
\hline Left-handed & I & Go to QIB \\
\hline Right-handed & 2 & Go to QIB \\
\hline Both & 3 & Go to QIB \\
\hline
\end{tabular}

1B. Which of the following injectable gonadotropin injection devices have you taught your patients to use in the last six months? Please tick all which apply. (Ask all, multicode allowed.)

\begin{tabular}{|c|c|c|}
\hline GONAL-f ${ }^{\circledR}$ pen (follitropin alfa) & 1 & Go to Q2A \\
\hline GONAL-f ${ }^{\circledast}$ syringe/vial (follitropin alfa) & 2 & Go to Q2C \\
\hline Luveris $^{\circledR}$ syringe/vial (lutropin alfa) & 3 & Go to Q2C \\
\hline Ovitrelle ${ }^{\circledR}$ prefilled syringe (choriogonadotropin alfa) & 4 & Go to $\mathrm{Q} 2 \mathrm{C}$ \\
\hline Puregon ${ }^{\circledR}$ pen (follitropin beta) & 5 & Go to Q2B \\
\hline Puregon ${ }^{\circledR}$ syringe/vial (follitropin beta) & 6 & Go to $\mathrm{Q} 2 \mathrm{C}$ \\
\hline Pregny ${ }^{\circledR}$ syringe/vial (chorionic gonadotropin) & 7 & Go to Q2C \\
\hline Bravelle ${ }^{\circledR}$ syringe/vial (urofollitropin) & 8 & Go to $\mathrm{Q} 2 \mathrm{C}$ \\
\hline Menopur ${ }^{\circledR}$ syringe/vial (menotropin) & 9 & Go to $\mathrm{Q} 2 \mathrm{C}$ \\
\hline Meriona ${ }^{\circledR}$ syringe/vial (menotropin) & 10 & Go to $\mathrm{Q} 2 \mathrm{C}$ \\
\hline Fostimon ${ }^{\circledR}$ syringe/vial (urofollitropin) & 11 & Go to $\mathrm{Q} 2 \mathrm{C}$ \\
\hline Choragon ${ }^{\circledR}$ syringe/vial (chorionic gonadotropin) & 12 & Go to $\mathrm{Q} 2 \mathrm{C}$ \\
\hline Others (write in) & 13 & Go to Q2C \\
\hline
\end{tabular}

2A. The following is a list of attributes relating to the current GONAL- $\mathrm{f}^{\circledR}$ pen. Please rate its performance on the following scale. (Randomize order of 2A, 2B, and 2C. Ask Q2A if code 01 (GONAL-f ${ }^{\circledR}$ pen) coded at Q1B. Single code per statement.)

1. Very low

2. Quite low

3. Neither low nor high

4. Quite high

5. Very high

\begin{tabular}{|l|l|}
\hline Range of possible doses which can be prescribed (due to permitted dose increments) & $\mathrm{I}$ \\
\hline Ease for the nurse to learn how to use & 2 \\
\hline Ease for the nurse to teach patients how to use & 3 \\
\hline Your confidence that the patient understands how to remove any large air bubbles before use & 4 \\
\hline Ease for patient to fit needle onto pen & 5 \\
\hline Ease for patient to read the dosing scale & 6 \\
\hline Your confidence in the patient's ability to calculate and set the correct dose & 7 \\
\hline Ease for patient to pull up and prime the injection button & 8 \\
\hline Ease for patient to push the injection button when injecting & 9 \\
\hline Ease for patient to administer the injection & 10 \\
\hline Ease for patient to check that the full dose has been injected & 11 \\
\hline Your confidence that the full dose has been injected when patients self-administer at home & 12 \\
\hline Ease of removing and discarding the needle & 13 \\
\hline Your confidence that the patient is able to correctly calculate any top-up dose needed after injection & 14 \\
\hline Patient's satisfaction with the number of steps involved in preparing/giving the injection & 15 \\
\hline Your confidence that the patient understands how to use the pen properly & 16 \\
\hline
\end{tabular}


2B. The following is a list of attributes relating to the current Puregon ${ }^{\circledR}$ pen. Please rate its performance on the following scale. (Ask Q2B if code 05 (Puregon ${ }^{\circledR}$ pen) coded at Q1B. Single code per statement.)

1. Very low

2. Quite low

3. Neither low nor high

4. Quite high

5. Very high

\begin{tabular}{|l|l|}
\hline Range of possible doses which can be prescribed (due to permitted dose increments) & $\mathrm{I}$ \\
\hline Ease for the nurse to learn how to use & 2 \\
\hline Ease for the nurse to teach patients how to use & 3 \\
\hline Your confidence that the patient understands how to remove any large air bubbles before use & 4 \\
\hline Ease for patient to assemble the pen (insert treatment cartridge) & 5 \\
\hline Ease for patient to fit needle onto pen & 6 \\
\hline Ease for patient to read the dosing scale & 7 \\
\hline Your confidence in the patient's ability to calculate and set the correct dose & 8 \\
\hline Ease for patient to push the injection button when injecting & 9 \\
\hline Ease for patient to administer the injection & 10 \\
\hline Ease for patient to check that the full dose has been injected & $\mathrm{II}$ \\
\hline Your confidence that the full dose has been injected when patients self-administer at home & 12 \\
\hline Ease of removing and discarding the needle & 13 \\
\hline Your confidence that the patient is able to correctly calculate any top-up dose needed after injection & 14 \\
\hline Patient's satisfaction with the number of steps involved in preparing/giving the injection & 15 \\
\hline Your confidence that the patient understands how to use the pen properly & 16 \\
\hline
\end{tabular}

2C. The following is a list of attributes relating to current syringes and vials. Please rate their performance on the following scale. (Ask Q2C if codes 02, 03, 04, 06, 07, 08, 09, 10, 11, and 12 (syringes and vials) coded at Q1B. Single code per statement.)

1. Very low

2. Quite low

3. Neither low nor high

4. Quite high

5. Very high

\begin{tabular}{|l|l|}
\hline Range of possible doses which can be prescribed (due to permitted dose increments) & $\mathrm{I}$ \\
\hline Ease for the nurse to learn how to use & 2 \\
\hline Ease for the nurse to teach patients how to use & 3 \\
\hline Your confidence that the patient understands how to remove any large air bubbles before use & 4 \\
\hline Ease for patient to fit needle onto syringe & 5 \\
\hline Ease for patient to read the dosing scale & 6 \\
\hline Ease for patient to mix the treatment in the vial & 7 \\
\hline Ease for patient to read the gradations on the clear reservoir holder & 8 \\
\hline Your confidence in the patient's ability to calculate and set the correct dose & 9 \\
\hline Ease for patient to administer the injection & 10 \\
\hline Ease for patient to check that the full dose has been injected & $\mathrm{II}$ \\
\hline Your confidence that the full dose has been injected when patients self-administer at home & 12 \\
\hline Ease of removing and discarding the needle & 13 \\
\hline Your confidence that the patient is able to correctly calculate any top-up dose needed after injection & 14 \\
\hline Patient's satisfaction with the number of steps involved in preparing/giving the injection & 15 \\
\hline Your confidence that the patient understands how to use the syringe properly & 16 \\
\hline
\end{tabular}




\section{Section 2}

Reactions to pen demonstration, to be completed after the training session. (Section divider, introduction to be shown to respondent.) Now, you will be shown a demonstration on how to use the new pen. * You will have the opportunity to try the new pen after the demonstration. Please click NEXT after you had a chance to try the new pen.

3. Below is a list of statements that you may or may not agree with. Please tick all that you agree with having had your training session. (Ask all, multicode allowed.)

\begin{tabular}{|l|l|l|}
\hline I found it easy to learn to use the pen & I & Go to Q4 \\
\hline I believe this new pen would be easy for me to teach my patients to use & 2 & Go to Q4 \\
\hline It will take me less time to teach my patients to use this new pen compared with current pens & 3 & Go to Q4 \\
\hline It is easy to remove large air bubbles from the new pen & 4 & Go to Q4 \\
\hline It is easier to read the dosing scale on this new pen compared with other pens/syringes & 5 & Go to Q4 \\
\hline There are fewer steps involved in preparing the pen for injection compared with current pens & 6 & Go to Q4 \\
\hline $\begin{array}{l}\text { I believe my patients will be able to prepare and inject in a shorter period of time using this pen compared } \\
\text { with current pens }\end{array}$ & 7 & Go to Q4 \\
\hline There is less room for error when setting/adjusting the dose with this new pen compared with current pens & 8 & Go to Q4 \\
\hline I am confident my patients will be able to regularly administer treatment at the correct dose using this pen & 9 & Go to Q4 \\
\hline I believe my patients will be more confident in using this new pen than other pens/syringes & I0 & Go to Q4 \\
\hline
\end{tabular}

4. How comfortable are you with each of the following? (Ask all, single code per statement.) For each attribute please indicate whether you are:

5. Very comfortable

4. Quite comfortable

3. Neutral

2. Quite uncomfortable

1. Very uncomfortable

\begin{tabular}{|l|l|l|}
\hline The comfort of holding the pen whilst injecting & I & Go to Q5 \\
\hline Pushing the dose setting knob when injecting & 2 & Go to Q5 \\
\hline The soft click sound when injecting & 3 & Go to Q5 \\
\hline Pressure required from thumb when injecting & 4 & Go to Q5 \\
\hline The zero reading on the dosing scale following injection, indicating the full dose has been injected & 5 & Go to Q5 \\
\hline The control of the pen whilst injecting & 6 & Go to Q5 \\
\hline
\end{tabular}

5. Please rate the new pen on each of the following attributes. (Ask all, single code per statement.)

5. Very high

4. Quite high

3. Neither low nor high

2. Quite low

1. Very low

\begin{tabular}{|l|l|l|}
\hline Range of possible doses which can be prescribed (due to permitted dose increments) & I & Go to Q6 \\
\hline Ease for the nurse to learn how to use & 2 & Go to Q6 \\
\hline Ease for the nurse to teach patients how to use & 3 & Go to Q6 \\
\hline Your confidence that the patient understands how to remove any large air bubbles before use & 4 & Go to Q6 \\
\hline Ease for patient to fit needle onto pen & 5 & Go to Q6 \\
\hline Ease for patient to read the dosing scale & 6 & Go to Q6 \\
\hline Ease for patients to read the gradations on the clear reservoir holder & 7 & Go to Q6 \\
\hline Your confidence in the patient's ability to calculate and set the correct dose & Go to Q6 \\
\hline
\end{tabular}

*The term "new pen" refers to the "redesigned follitropin alfa pen." 
(Continued)

\begin{tabular}{|l|l|l|}
\hline Ease for patient to push the dose setting knob when injecting & 9 & Go to Q6 \\
\hline Ease for patient to administer the injection & I0 & Go to Q6 \\
\hline Ease for patient to check that the full dose has been injected & II & Go to Q6 \\
\hline Your confidence that the full dose has been injected when patients self-administer at home & I2 & Go to Q6 \\
\hline Ease of removing and discarding the needle & I3 & Go to Q6 \\
\hline Your confidence that the patient is able to correctly calculate any top-up dose needed after injection & I4 & Go to Q6 \\
\hline Patient's satisfaction with the number of steps involved in preparing/giving the injection & I5 & Go to Q6 \\
\hline Your confidence that the patient understands how to use the pen properly & 16 & Go to Q6 \\
\hline
\end{tabular}

6. Please rank the importance of the following attributes if recommending any injection device for gonadotropins to a fellow fertility nurse like yourself. (Ask all, provide a ranking ladder that respondent can drag and drop each attribute onto.)

\begin{tabular}{|c|c|c|}
\hline Range of possible doses which can be prescribed (due to permitted dose increments) & I & Go to Q7 \\
\hline Ease for the nurse to learn how to use & 2 & Go to Q7 \\
\hline Ease for the nurse to teach patients how to use & 3 & Go to Q7 \\
\hline Your confidence that the patient understands how to remove any large air bubbles before use & 4 & Go to Q7 \\
\hline Ease for patient to fit needle onto pen & 5 & Go to Q7 \\
\hline Ease for patient to read the dosing scale & 6 & Go to Q7 \\
\hline Ease for patients to read the gradations on the clear reservoir holder & 7 & Go to Q7 \\
\hline Your confidence in the patient's ability to calculate and set the correct dose & 8 & Go to Q7 \\
\hline Ease for patient to push the dose setting knob when injecting & 9 & Go to Q7 \\
\hline Ease for patient to administer the injection & 10 & Go to Q7 \\
\hline Ease for patient to check that the full dose has been injected & 11 & Go to Q7 \\
\hline Your confidence that the full dose has been injected when patients self-administer at home & 12 & Go to Q7 \\
\hline Ease of removing and discarding the needle & 13 & Go to Q7 \\
\hline Your confidence that the patient is able to correctly calculate any top-up dose needed after injection & 14 & Go to Q7 \\
\hline Patient's satisfaction with the number of steps involved in preparing/giving the injection & 15 & Go to Q7 \\
\hline Your confidence that the patient understands how to use the device properly & 16 & Go to Q7 \\
\hline
\end{tabular}

7. (Ask all, single code per statement.) Overall, how easy do you think it will be to teach patients how to use the new pen compared with:

5. Much easier to teach

4. Somewhat easier to teach

3. No better nor worse

2. Somewhat harder to teach

1. Much harder to teach

\begin{tabular}{|l|l|l|l|}
\hline The current GONAL- ${ }^{\circledast}$ pen? & I & Go to Q8 & Only show this option if code \\
\hline The current Puregon ${ }^{\circledR}$ pen? & 2 & Go to Q8 & \\
\hline Current syringes and vials? & 3 & Go to Q8 & \\
\hline
\end{tabular}

8. How confident are you in teaching patients how to use the new pen after your training? (Ask all, single code only.)

5. Very confident

4. Quite confident

3. Neutral

2. Not very confident

1. Not at all confident 
9. Which of the following aspects of the new pen, if any, do you see as advantages over current injection methods. Please tick all that apply. (Ask all, multicode.)

\begin{tabular}{|l|l|l|}
\hline Transparent (clear) reservoir holder & I & 2 \\
\hline Gradations on the reservoir holder & Go to QI0 & 3 \\
\hline Needle attachment and removal & Go to QI0 & Go to QI0 \\
\hline Flexibility to readjust dose (if set dose is too high/low) & 5 \\
\hline Single press release for injection & Go to QI0 & 6 \\
\hline The soft click sound when injecting & Go to QI0 & 7 \\
\hline Pressure required from thumb when injecting & Go to QI0 \\
\hline Visibility of dosing window & Go to QI0 \\
\hline Ability to see any top-up dose needed after injection & 9 \\
\hline The zero reading on the dosing scale following injection, indicating the full dose has been injected & Go to QI0 \\
\hline Additional confidence that the full dose has been injected compared with current pens/syringes & Go to QI0 \\
\hline
\end{tabular}

\section{Section 3}

Evaluation of the pen and how easy it was to train patients to use it - to be completed after the nurses train the patients to use the pen. (Section divider, introduction to be shown to respondent.) Now, you will have the opportunity to demonstrate and train some patients on how to use the new pen. Please click NEXT after you have trained the patients on how to use the new pen.

10. On a scale of $1-5$, how easy has it been to teach patients to perform each of the following functions of the new pen? (Ask all, single code per statement.)

5. Very easy

4. Somewhat easy

3. Neither easy nor difficult

2. Somewhat difficult

1. Very difficult

\begin{tabular}{|l|l|l|}
\hline How to to remove any large air bubbles before use & I & Go to QII \\
\hline How to fit needle on pen & 2 & Go to QII \\
\hline How to read the gradations on the clear reservoir holder & 3 & Go to QII \\
\hline How to read the dosing scale & 4 & Go to QII \\
\hline How to calculate and set the dose & 5 & Go to QII \\
\hline How to push the dose setting knob when injecting & 6 & Go to QII \\
\hline How to calculate/administer a top-up dose when needed & 7 & Go to QII \\
\hline How to remove and discard the needle & 7 & Go to QII \\
\hline Overall process of self-administering a dose from start to finish & 8 & Go to QII \\
\hline Others (please state) & 9 & Go to QII \\
\hline
\end{tabular}

11. Based on your experience with the new pen today, to what extent would you be likely to recommend it to a fellow fertility nurse like yourself? (Ask all, single code only.)

5. Very likely

4. Likely

3. Neither likely nor unlikely

2. Unlikely

1. Very unlikely

12. Now that you have trained some patients to use the new pen, to what extent do you agree with the following statements? (Ask Q12 if code 01 and/or code 05 (pens) coded at Q1B.)

5. Strongly agree

4. Somewhat agree 
3. Neither agree nor disagree

2. Somewhat disagree

1. Strongly disagree

\begin{tabular}{|l|l|l|}
\hline It will take me less time to teach my patients to use this new pen compared with current pens & I & Go to QI3 \\
\hline There are fewer steps involved in preparing and giving the injection with the new pen compared with current pens & 2 & Go to QI3 \\
\hline There is less room for error when setting/adjusting the correct dose with this new pen compared with current pens & 3 & Go to QI3 \\
\hline I believe my patients will be able to regularly administer the correct dose with this new pen & 4 & Go to QI3 \\
\hline $\begin{array}{l}\text { I believe my patients will be able to prepare and give the injection using this new pen in a shorter period of time } \\
\text { compared with current pens }\end{array}$ & 5 & Go to QI3 \\
\hline I believe my patients will be able to confidently calculate/administer any top-up dose needed with this pen & 6 & Go to QI3 \\
\hline I believe my patients will be confident in using this new pen with minimal queries once they are trained by me & 7 & Go to QI3 \\
\hline
\end{tabular}

13. Overall, how easy do you believe is it to teach patients to use the new pen compared with current pens? (Ask all, single code.)

5. Much easier to teach

4. Somewhat easier to teach

3. Neither harder nor easier than current devices

2. Somewhat harder to teach

1. Much harder to teach

14. Based on ease of teaching, if you only had one choice, which of the following would you prefer to teach patients how to use for their injectable follicle-stimulating hormone medication? (Ask all, single code.)

\begin{tabular}{|l|l|l|}
\hline Current GONAL-f ${ }^{\circledast}$ pen & I & Go to QI5 \\
\hline Current Puregon ${ }^{\circledR}$ pen & 2 & Go to QI5 \\
\hline Current syringes and vials & 3 & Go to QI5 \\
\hline This new pen & 4 & Go to QI5 \\
\hline
\end{tabular}

15. This new pen will be produced for Merck Serono injectable gonadotropins. In the future, additional gonadotropins will be available in separate pens, just like this. To what extent do you agree with each of the following statements? (Ask all, single code per statement.)

5. Strongly agree

4. Somewhat agree

3. Neither agree nor disagree

2. Somewhat disagree

1. Strongly disagree

\begin{tabular}{|l|l|l|}
\hline I am more likely to recommend injectable gonadotropins from Merck Serono if they each come in pens like this one & I & Finish \\
\hline Having the same pen format for a range of injectable gonadotropins will make it easier for me to teach my patients to self-inject & 2 & Finish \\
\hline Having the same pen format for a range of injectable gonadotropins will significantly reduce my teaching time with patients & 3 & Finish \\
\hline Having the same pen format for a range of injectable gonadotropins will make it easier for patients to learn to self-inject & 4 & Finish \\
\hline Given a choice, patients would ideally prefer to use the same pen format for all of their injectable gonadotropins & 5 & Finish \\
\hline $\begin{array}{l}\text { Having the same pen format for a number for the different injectable gonadotropins would reduce mistakes when patients } \\
\text { self-administer at home }\end{array}$ & 6 & Finish \\
\hline This will increase my likelihood to recommend Merck Serono products to the physician & 7 & Finish \\
\hline
\end{tabular}

Finally, can we contact you again to discuss any points that may be raised following your participation in this research project?

$\begin{array}{lll}\text { Answer: } & \text { Yes } & \text { No }\end{array}$ 


\section{Appendix 2}

Patient questionnaire. Approximate duration 15 minutes.

\section{Section I}

Evaluation of previously used devices.

1A. Are you left or right-handed? (Ask all, single code only.)

\begin{tabular}{|l|l|l|}
\hline Left-handed & I & Go to QIB \\
\hline Right-handed & 2 & Go to QIB \\
\hline Both & 3 & Go to QIB \\
\hline
\end{tabular}

1B. Do you currently use, or have you ever used in the past, a self-administered injectable medication for fertility treatment? (Ask all, single code only.)

\begin{tabular}{|l|l|l|l|}
\hline Yes & I & Go to QIC & (Code as “injection experienced") \\
\hline No & 2 & Go to Q2 & (Code as "injection naive") \\
\hline
\end{tabular}

1C. Which of the following fertility treatments have you used in the past six months? Please tick all which apply. (Ask all, multicode allowed.)

\begin{tabular}{|c|c|c|}
\hline GONAL-f ${ }^{\oplus}$ pen (follitropin alfa) & 1 & Go to QID \\
\hline GONAL-f ${ }^{\oplus}$ syringe/vial (follitropin alfa) & 2 & Go to QID \\
\hline Luveris $^{\circledR}$ syringe/vial (lutropin alfa) & 3 & Go to QID \\
\hline $\begin{array}{l}\text { Ovitrelle }{ }^{\circledR} \text { prefilled syringe (choriogonadotropin } \\
\text { alfa) }\end{array}$ & 4 & Go to QID \\
\hline Puregon ${ }^{\circledR}$ pen (follitropin beta) & 5 & Go to QID \\
\hline Puregon ${ }^{\circledast}$ syringe/vial (follitropin beta) & 6 & Go to QID \\
\hline Pregny ${ }^{\circledR}$ syringe/vial (chorionic gonadotropin) & 7 & Go to QID \\
\hline Bravelle $^{\circledR}$ syringe/vial (urofollitropin) & 8 & Go to QID \\
\hline Menopur $^{\circledast}$ syringe/vial (menotropin) & 9 & Go to QID \\
\hline Meriona $\mid{ }^{\circledR}$ syringe/vial (menotropin) & 10 & Go to QID \\
\hline Fostimon ${ }^{\circledR}$ syringe/vial (urofollitropin) & 11 & Go to QID \\
\hline $\begin{array}{l}\text { Choragon }^{\circledR} \text { syringe/vial (chorionic } \\
\text { gonadotropin) }\end{array}$ & 12 & Go to QID \\
\hline Others (write in) & 13 & Go to QID \\
\hline
\end{tabular}

1D. Which of the following injection methods do you currently use to inject your fertility medication? Please tick all which apply. (Ask all, multicode allowed.)

\begin{tabular}{|c|c|c|}
\hline GONAL-f ${ }^{\circledR}$ pen & I & Go to $\mathrm{Q} 2$ \\
\hline Puregon ${ }^{\circledR}$ pen & 2 & Go to Q2 \\
\hline Syringe and vial & 3 & Go to Q2 \\
\hline Prefilled syringe & 4 & Go to Q2 \\
\hline
\end{tabular}

\section{Section 2}

Evaluation of new pen* and how easy it is to learn to use. (To be completed after the patient has received the demonstration/training from the nurse and has had a chance to try the pen themselves.) All injection-experienced and injection-naive patients to answer all questions in this section. (Section divider, introduction to be shown to respondent.) Now, you will be shown a demonstration on how to use the new pen by a qualified fertility nurse. You will have the opportunity to try the new pen after the demonstration. Please click NEXT after you had a chance to try the new pen after the demonstration.

*The term "new pen" refers to the "redesigned follitropin alfa pen." 
2. Which of the following aspects of the new pen did you find easy to learn? Please select all which apply. (Ask all, multicode.)

\begin{tabular}{|l|l|l|}
\hline The whole process was easy to follow and I had no trouble learning how to use the new pen & $\mathrm{I}$ & $\mathrm{Go}$ to Q3 \\
\hline Learning how to fit the needle onto the pen & 2 & Go to Q3 \\
\hline Learning how to remove any large air bubbles before use & 3 & Go to Q3 \\
\hline Learning how to set the dose & 4 & Go to Q3 \\
\hline Learning how to read the dosing scale in the dose window on the side of the pen & 5 & Go to Q3 \\
\hline Learning how to read the gradations on the clear reservoir holder & 6 & Go to Q3 \\
\hline Learning how to push the dose setting knob when injecting & 7 & Go to Q3 \\
\hline Learning how to check the full dose has been delivered & 8 & Go to Q3 \\
\hline Learning how to calculate/administer a top-up dose when needed & 9 & Go to Q3 \\
\hline Learning how to remove and discard the needle & I0 & Go to Q3 \\
\hline Others (write in) & $\mathrm{II}$ & Go to Q3 \\
\hline
\end{tabular}

3. How comfortable are you with the following? (Ask all, single code per statement.) For each attribute please indicate whether you are:

5. Very comfortable

4. Quite comfortable

3. Neither comfortable nor uncomfortable

2. Quite uncomfortable

1. Very uncomfortable

\begin{tabular}{|l|l|l|}
\hline The comfort of holding the pen whilst injecting & I & Go to Q4 \\
\hline Pushing the dose setting knob when injecting & 2 & Go to Q4 \\
\hline The soft click sound when injecting & 3 & Go to Q4 \\
\hline Pressure required from thumb when injecting & 4 & Go to Q4 \\
\hline The zero reading on the dosing scale following injection, indicating the full dose has been injected & 5 & Go to Q4 \\
\hline The control of the pen whilst injecting & 6 & Go to Q4 \\
\hline
\end{tabular}

4. Which of the following aspects, if any, do you see as advantages when learning how to use the new pen? Please tick all that apply. (Ask all, multicode.)

\begin{tabular}{|l|l|l|}
\hline Transparent (clear) reservoir holder & I & Go to Q5 \\
\hline Gradations on the clear reservoir holder & 2 & Go to Q5 \\
\hline Needle attachment and removal & 3 & Go to Q5 \\
\hline Flexibility to readjust dose (if set dose is too high/low) & 4 & Go to Q5 \\
\hline Single press release for injection & 5 & Go to Q5 \\
\hline Soft click sound when injecting & 6 & Go to Q5 \\
\hline Pressure required from thumb when injecting & 7 & Go to Q5 \\
\hline Visibility of dosing window & 8 & Go to Q5 \\
\hline Ability to view any top-up dose needed after injection & 9 & Go to Q5 \\
\hline The zero reading on the dosing scale following injection, indicating the full dose has been injected & I0 & Go to Q5 \\
\hline $\begin{array}{l}\text { Additional confidence that the full dose has been injected, compared with your current method of } \\
\text { injection }\end{array}$ & II & Go to Q5 \\
\hline
\end{tabular}

\section{Section 3}

Comparison of new pen with currently used pen/syringe. Only ask for those coded 01 at Q1B. Only injection-experienced patients to answer all questions in this section. 
5. The following is a list of attributes relating to the new pen and the injection pen, syringe/vial or prefilled syringe which you currently use. (Allow comparison between new pen and each device coded at Q1D, show all devices on screen to allow direct comparison.) Need to add option of prefilled syringe to link. Please rate their performance on a scale of $1-5$ where:

1. Very low

2. Quite low

3. Neither low nor high

4. High

5. Very high

\begin{tabular}{|l|l|l|}
\hline Easy to learn how to use & I & Go to Q6 \\
\hline Easy to learn how to remove any large air bubbles before use & 2 & Go to Q6 \\
\hline Easy to learn how to fit the needle onto the pen & 3 & Go to Q6 \\
\hline Easy to learn how to read the dosing scale & 4 & Go to Q6 \\
\hline Easy to learn how to read the gradations on the clear reservoir holder & 5 & Go to Q6 (Ask for new pen only) \\
\hline Easy to learn how to calculate and set the dose & 6 & Go to Q6 \\
\hline Flexibility to readjust dose (if set dose is too high/low) & 7 & Go to Q6 \\
\hline Easy to learn how to push the dose setting knob when injecting & 8 & Go to Q6 \\
\hline Easy to learn how to administer the injection & 9 & Go to Q6 \\
\hline Easy to check that the full dose has been injected & 10 & Go to Q6 \\
\hline Easy to remove and discard the needle & II & Go to Q6 \\
\hline Easy to calculate any top-up dose needed after injection & 12 & Go to Q6 \\
\hline Number of steps involved in preparing/giving the injection & 13 & Go to Q6 \\
\hline
\end{tabular}

6. Now that you are trained and have tried using the new pen, to what extent do you agree with the following statements? (Single code per statement.)

5. Strongly agree

4. Somewhat agree

3. Neither agree nor disagree

2. Somewhat disagree

1. Strongly disagree

\begin{tabular}{|l|l|l|}
\hline It was easier to learn how to use this new pen compared with my current injection method & I & Go to Q7 \\
\hline It is easier to remove large air bubbles from the new pen compared with my current injection method & 2 & Go to Q7 \\
\hline It is easier to read the dosing scale on this new pen compared with my current injection method & 3 & Go to Q7 \\
\hline It takes less time for me to prepare the new pen for my injection compared to my current injection method & 4 & Go to Q7 \\
\hline $\begin{array}{l}\text { There are fewer steps involved in preparing/giving the injection with the new pen compared with my } \\
\text { current injection method }\end{array}$ & 5 & Go to Q7 \\
\hline $\begin{array}{l}\text { There is less room for error in setting/adjusting the correct dose with this new pen compared } \\
\text { with my current injection method }\end{array}$ & 6 & Go to Q7 \\
\hline $\begin{array}{l}\text { I am more confident I will be able to administer the correct dose using this new pen compared } \\
\text { with my current injection method }\end{array}$ & 7 & Go to Q7 \\
\hline $\begin{array}{l}\text { I am more confident I will be able to calculate any top-up dose needed with this new pen, compared } \\
\text { with my current injection method }\end{array}$ & 8 & Go to Q7 \\
\hline I would be more confident in using this new pen than my current injection method & 9 & Go to Q7 \\
\hline I am confident I can self-administer using this new pen without any further help from my nurse in the future & I0 & Go to Q7 \\
\hline $\begin{array}{l}\text { There is less wastage of medication compared with my current injection method as I will use all the medication } \\
\text { in the pen before starting a new pen }\end{array}$ & II & Go to Q7 \\
\hline
\end{tabular}


7. Based on your experience today, which of the following statements best reflects your opinion of this new pen as a delivery system for an injectable fertility treatment? (Single code only.)

\begin{tabular}{|l|l|l|}
\hline I believe this pen is definitely better than the pens and/or syringes of which I have experience & I & Go to Q8 \\
\hline I believe this is somewhat better than the pens and/or syringes of which I have experience & 2 & Go to Q8 \\
\hline I believe this is neither better nor worse than pens and/or syringes of which I have experience & 3 & Go to Q8 \\
\hline I think this pen is not quite as good as the pen and/or syringes of which I have experience & 4 & Go to Q8 \\
\hline This pen is inferior to the pen and/or syringes of which I have experience & 5 & Go to Q8 \\
\hline
\end{tabular}

\section{Section 4}

Agreement with statements and preference for new pen. (All patients [injection-experienced and injection-naive] to answer all questions in this section.)

8. Now that you are trained and have tried using the new pen, to what extent do you agree with the following statements? (Single code per statement.)

5. Strongly agree

4. Somewhat agree

3. Neither agree nor disagree

2. Somewhat disagree

1. Strongly disagree

\begin{tabular}{|l|l|l|}
\hline I believe that this new pen will ensure I inject the full dose properly when I self-administer at home & I & Go to Q9 \\
\hline I believe this new pen will ensure I calculate and set the correct dose when I self-administer at home & 2 & Go to Q9 \\
\hline I am comfortable with the number of steps involved in preparing and giving the injection & 3 & Go to Q9 \\
\hline
\end{tabular}

9. Assuming your nurse or doctor gave you a choice, which of the following would you prefer to use in the future for all your injectable fertility medications? (Injection-experienced patients only to answer, single code only.)

\begin{tabular}{|l|l|l|}
\hline My current method of injection - pen & I & Finish \\
\hline My current method of injection - syringe and vial & 2 & Finish \\
\hline This new pen & 3 & Finish \\
\hline
\end{tabular}

Finally, can we contact you again to discuss any points that may be raised following your participation in this research project?

Answer: $\quad$ Yes $\quad$ No

\section{Publish your work in this journal}

Patient Preference and Adherence is an international, peer-reviewed, open access journal focusing on the growing importance of patient preference and adherence throughout the therapeutic continuum. Patient satisfaction, acceptability, quality of life, compliance, persistence and their role in developing new therapeutic modalities and compounds to optimize clinical outcomes for existing disease states are major areas of interest. This journal has been accepted for indexing on PubMed Central. The manuscript management system is completely online and includes a very quick and fair peer-review system. Visit http://www.dovepress.com/ testimonials.php to read real quotes from published authors. 